\title{
Dynamic Game Research on Multiple Subjects in the Real Estate Market of China
}

\author{
Mingli Gong \\ School of Economics, Jinan University, Guangzhou, China \\ Email: sherogml@126.com
}

How to cite this paper: Gong, M.L. (2017) Dynamic Game Research on Multiple Subjects in the Real Estate Market of China. Open Journal of Applied Sciences, 7, 184-195.

https://doi.org/10.4236/ojapps.2017.74016

Received: March 17, 2017

Accepted: April 27, 2017

Published: April 30, 2017

Copyright $\odot 2017$ by author and Scientific Research Publishing Inc. This work is licensed under the Creative Commons Attribution International License (CC BY 4.0).

http://creativecommons.org/licenses/by/4.0/

(c) (7) Open Access

\begin{abstract}
In order to analyze the deep-routed reason for the failure of the real estate market regulation policy, this paper established an incomplete information tri-game model in which central government, local government and the real estate developer were chosen as three main research objects. Based on the analysis of their interest appeals under the assumption of rational economic man, we found that it was the difference of interest appeals of central and local governments as well as the real estate developers that caused the game among the three participants. This, however, led to the failure of the macro-control at last. Strengthening the supervision of central government and reducing its cost at the same time, what's more, improving the efficiency of the supervision and increasing the punishment of the rent-seeking behavior between local government and the real estate developers will contribute to improve the implementation status of the regulation and control policy. We suggest the authorities improve the government political achievement appraisal system and reform the current system of benefits distribution; moreover, reform the existing regulatory system and strength the regulatory role of media and the third-party so as to promote the healthy development of the real estate market.
\end{abstract}

\section{Keywords}

The Real Estate Market, Failure of Macro-Control, Incomplete Information, Dynamic Tri-Game Model

\section{Introduction}

Under the background of the construction of new-type urbanization, the real estate market has become one of the most arresting markets. As a business closed to urbanization, the real estate market achieved rapid development over the years. However, there are many problems such as artificially high house prices, 
the real estate bubble, unreasonable housing structure and so on. As a business closed to urbanization, the real estate market achieved rapid development over the years. However, there are many problems such as artificially high house prices, the real estate bubble, unreasonable housing structure and so on. In recent years, the country has issued relevant policies to regulate the real estate market, which include purchase limits, interest rates raising, price ceiling, second-hand housing sales tax etc. Nevertheless, the essential question remains unresolved after various regulation, people still do not meet state living in peace and contentment. At present, there is an "economics paradox" in real estate market of our country, which says that the house supply increased sharply after the implement of the macro-control policy but the effective demand of house is insufficiency along with the rising housing prices [1]. Based on this situation, it's meaningful and significant to analyze the relationship of interest game between central government, local governments, property developers and other stakeholders for central government improving regulatory efficiency, local governments implementing regulatory policy and promoting price stability.

Generally, the scholars analyze this phenomenon from the perspective of the equilibrium of demand and supply, which is the price analysis method in the neoclassical economics [2] [3] [4] [5] [6]. However, the neoclassical analysis is established on the hypothesis that the participants are all rational economic men who have complete information, meanwhile, the market is clear. Nevertheless, compared to other markets, it's quite difficult to set up these assumptions in the real estate market. There exist significant defects in the analysis of Chinese real estate market based on this method.

The game theory has been widely applied to explain many complex phenomenon in economics since it emphasizes on the micro foundation and clear logical deduction.

Faced with the reality that the housing price is sustained rising but the corresponding price-control policy is frequently failed, more and more explorers pay attention to this issue and analyzed it by the game theory. Some researchers chose two participants of the real estate market in their game model, either the central government and the local government, or the local government and the real estate developers [7] [8] [9] [10]. However, the rapid rise of housing price in the real estate market of China is the result of the complex game of the central government, local governments, developers, banks, speculators, self-residents and many other participants [11]. Then the scholars turn to analyze the multiparty game in the real estate market [12]-[16]. For example, Yang et al. chose the government, developer and the consumers in the real estate market as research objectives and established a tri-game model [12]. As for the reason for the appearance of game in the real estate market, the mainstream view now is attributed to the reform of fiscal centralization and tax sharing system. In order to break the plight of the current real estate market, Peng, K.T. pointed out that the central government should scan the development of real estate industry from a spatial perspective, increase the attention of block economy and spatial viscous 
of real estate market, establish a long-term mechanism of housing control, improve the supply and demand and reverse market expectations to raise policy performance [17].

From what has been discussed above we can see, although there are some discussions about the reason why real estate macroeconomic regulation and control can't play an effective role and house prices are difficult to reduce in current literature, they only analyze it from the perspective of game between central governments and local government or local governments and real estate developers. In other words, they didn't see the three elements as an organic whole linkage. Now, this article will make some improvements based on the current research by comprehensively considering the relationship among central government, local governments and real estate developers from the perspective of game theory, and establishing a dynamic tri-game model in the condition of incomplete information at the same time to seek for the underlying reasons why the macroeconomic regulation and control policy in real estate market is not ideal. Last but not least, we'd like to put forward some useful suggestions for the authorities.

\section{Behavior Analysis of the Participants in Real Estate Market}

\subsection{The Behavior Analysis of Central Government}

The central government, which is the representative of the whole society interest, need to put forward a series of macroeconomic regulation and control policies to ensure the normal and stable development of the economy, and avoid the sharp economic fluctuations caused by house prices soaring or plunging at the same time. The central government is ought to curb excessive house price increases to keep the housing price fluctuating within a reasonable range and promote the healthy and stable development of the real estate market.

In the face of the overheated real estate market, the central government must introduce a series of appropriate regulatory policies to curb the momentum of its crazy rise to maintain the balanced development of the entire real estate market and ease the pressure of ordinary residents purchase a house. However, the implement of the policy must rely on the help of local governments nationwide. In fact, the interest demands of the central government and local governments are not always consistent, and there will be a game between the governments when they have conflicts over interest distribution.

\subsection{The Behavior Analysis of Local Government}

The scope of the powers (expenditure) of the central and local government and the tax types of central finance and local finance are divided in the tax system reform in 1994. This tax system assured the increase of the central fiscal revenue and the sustained growth of the national economy, but also brought a lot of problems at the same time due to that the financial authority and powers does not match perfectly. The central government holds a large number of finance resource, while the local government owns limited finance power but has un- 
equal administrative power. Thus, some local governments have to raise funds in order to meet the needs of local economic development and the construction of public utilities by themselves. In the convenience of information and geographical, the local government could promote the development of local economy through the operation of land. Worse still, the real estate industry has already become a very important factor in local governments' performance examination and fiscal revenue because of its high industrial relevancy and great contribution to GDP. Indeed, the so-called "land-finance" is so common in China that many provinces rely heavily on the real estate industry. To some extent, this entrapped the local governments to play a game with the central government taking the risk of being punished.

Based on the analysis above, we can draw a conclusion that the local government always plays the role of policy enforcer in macro policy mechanism in our country, while they are 'economic man' in the real estate market. It's granted that they will chase for the maximization of their interests. Therefore, once the divergence of control target appears when carrying out the price control policy, the local governments will have strong negative incentive and even conspire with the real estate developers to do rent-seeking activities, which lead to the frequent failure of regulation policy while the house prices continue to rise without control. According to the statement of the famous economists Buchanan and Krueger, the term "rent" refers to the surplus income of a few privileged people when the government use their administration power to intervene and control the economic activities of enterprises and individuals, and their behavior of seeking for rent is called rent-seeking. In this paper, the rent-seeking activity means the phenomenon that the local government and the real estate developers collusion to get some benefits and hinders the implementation of the price control policies, through which the real estate developers could gain more income from the high house price while the local government enjoys the rent from the developers and even career promotion as local economy get developed in the prosperous land finance.

\subsection{The Behavior Analysis of Real Estate Developers}

For real estate developers, on the one hand, they are demanders in land market who should make full use of the binding system and other market elements in order to get land resources from local government with least cost. Of course, they are also responsible for multiple work such as original resident relocation, land consolidation and housing construction with a lot of manpower, material resources and financial resources. On the other hand, they are also the supplier in commercial housing who hold a lot of houses in the secondary market of real estate. To some extent, they have formed a powerful force which can even affect regulation policies formulated by the central government. In order to obtain more profits, real estate developers make feint of demand by hype and artificially reduce the housing supply. They purchase massive land but hoard them for speculation by blocking the supply and demand information instead of selling 
them out. In the end, they create tension factitiously to improve buyers' expectations of housing prices and achieve the goal of pushing up house prices eventually.

In addition, the estate agents also seized the point of view that local government is eager to expand the territory of the city and develop local economy, thus they will try their best to conspire the rent-seeking activity with the local government. This, however, not only affects the execution efficiency of macroeconomic regulation, but also severely damaged the normal order of the real estate market and eventually led to the rising house prices.

\section{Incomplete Information Tri-Game Model}

According to the analysis above, we make some definitions as follows:

In the condition of incomplete information, the set of tactics of the central government is $C \in\left\{Y_{0}, N_{0}\right\}$, in which $Y_{0}$ means the central government supervises the implementation of local governments and $N_{0}$ means there's no supervision. The set of tactics made by local government is $L \in\left\{Y_{1}, N_{1}\right\}$, where $Y_{1}$ means that the local government implement the policy strictly and doesn't have rent-seeking activities with the real estate developers, while $N_{1}$ means there exists irregularities. The set of tactics made by real estate developers is $D \in\left\{Y_{2}, N_{2}\right\}$, in which $Y_{2}$ means they have rent-seeking activities with the local government while $\mathrm{N}_{2}$ means there's no irregularity.

\subsection{Hypothesis}

In order to build the game model, we make the following hypothesis:

- All the participants in the real estate market-the central government, the local government and the real estate developers are considered as economic man in the sense of economics who pursuit the maximization of self-interest;

- the economic development level parameter in every main participant's utility function depends on the average level of national economic;

- All functions listed in this game model are liner;

- The regulation of the central government and the rent-seeking between local governments and real estate developers are all mutually independent events

- Local governments have natural information advantages, in other words, central government is difficult to completely monitor the behavior of local government. The regulation of central government is not always effective because the feedback mechanism of local government for the policy implementation effect is more perfect;

- Other participants' influence is slighter than central government, local governments and real estate developers, as a result, we ignore theirs effects on the real estate market in order to simplify the model here.

\subsection{Parameters}

- $X$ : The policy conducted by the central government to control the rising house price. Once executed effectively, the expected utility function is 
$U(X)=k X$, and $k$ is the utility coefficient of the implemented policy, $k \geq 1$.

- $\alpha$ : The revenue share of the central government after the implementation of the policy, accordingly, the benefit ratio of local governments is $1-\alpha$, $\alpha \in(0,1)$

- $\varepsilon$ : The degree of violation of local governments, $\varepsilon \in(0,1)$. It means that local government enforce the policy strictly if $\varepsilon=0$. Otherwise, the bigger $\varepsilon$ is, the less the policy is implemented by the local government. Besides, the irregularities will weaken the utility of policy $X$ to be $(1-\varepsilon) k X$.

- $\quad \beta$ : The benefit coefficient of rent-seeking for the local government when it cooperates with the real estate developers, and the rent is expressed as $\beta \varepsilon X$.

- $\quad \gamma$ : The benefit coefficient of rent-seeking for the real estate developers when they cooperate with the local government, and the revenue is expressed as $\gamma \varepsilon X$.

- $\omega$ : The coefficient of negative impact undertook by central government because of the rent-seeking between local governments and real estate developers. Because the incomplete implementation of policy $X$ will lead to adverse consequences such as the real estate market's instability as well as the social instability, the effectiveness of the central government will be $\omega \varepsilon X$.

- A: The cost of the supervision of the central government to local governments.

- $Q_{0}$ : The pay under the policy $X$ when real estate developers don't have rent-seeking activities.

- $\quad M$ : Once the violations of local government are discovered, they shall be sentenced to a fine as much as $M$ times of their illegal income, which means $M \beta \varepsilon X$.

- $\quad N$ : Once the rent-seeking between real estate developers and local governments is discovered, the real estate developers shall be sentenced to a fine as much as $N$ times of their illegal income, which means $N \gamma \varepsilon X$.

- $\quad p$ : The probability of the existence of rent-seeking between local governments and real estate developers.

- $q$ : The probability of the central government taking regulatory measures to local government.

- $U C_{i}: i=1,2,3, \cdots$ stands for central government's revenue in the $i$-th situation.

- $U L_{i}: i=1,2,3, \cdots$ stands for local government's revenue in the $i$-th situation.

- $U D_{i}: i=1,2,3, \cdots$ stands for real estate developers' revenue in the $i$-th situation.

\subsection{Modeling}

Based on the hypothesis and parameters above, we can get the following game situations and the corresponding payment situation of central government, local government and the real estate developers.

I. There is no rent-seeking behavior between the local government and the 
real estate developers, while the central government doesn't supervise the implementation of the local government. In this situation, both the central and local government can achieve the maximization of benefit as the policy $X$ is thoroughly carried out, but the real estate developer could only get a low profile. The payment is showed below:

$$
U C_{1}=\alpha k X, U L_{1}=(1-\alpha) k X, U D_{1}=Q_{0} .
$$

II. There is rent-seeking behavior between the local government and the real estate developers, while the central government doesn't supervise the implementation of the local government. In this situation, the effectiveness of the central government will reduce $\omega \varepsilon X$ because the policy $X$ isn't thoroughly carried out. Meanwhile the local government can get the extra rent $\beta \varepsilon X$, and the real estate developer can also earn extra revenue of $\gamma_{\varepsilon} X$ before the rent. The payment is showed below:

$$
\begin{aligned}
& U C_{2}=(1-\varepsilon) \alpha k X-\omega \varepsilon X \\
& U L_{2}=(1-\varepsilon)(1-\alpha) k X+\beta \varepsilon X \\
& U D_{2}=Q_{0}-\beta \varepsilon X+\gamma \varepsilon X
\end{aligned}
$$

III. There is no rent-seeking behavior between the local government and the real estate developers, while the central government supervises the implementation of the local government. In this situation, the central government can earn the full profit of the policy $\mathrm{X}$ as it is thoroughly carried out, but should pay A for the cost of supervision. The payment is showed below:

$$
\begin{aligned}
& U C_{3}=\alpha k X-A \\
& U L_{3}=(1-\alpha) k X \\
& U D_{3}=Q_{0}
\end{aligned}
$$

IV. There is rent-seeking behavior between the local government and the real estate developers, while the central government supervises the implementation of the local government and find its irregularities. In this situation, both the local government and the real estate developer will be punished and pay $M \beta \varepsilon X$ and $N \gamma \varepsilon X$ for their behaviors. The central government also need to pay A for the cost of supervision. The payment is showed below:

$$
\begin{aligned}
& U C_{4}=(1-\varepsilon) \alpha k X+M \beta \varepsilon X+N \gamma \varepsilon X-A \\
& U L_{4}=(1-\varepsilon)(1-\alpha) k X+(1-M) \beta \varepsilon X \\
& U D_{4}=Q_{0}-\beta \varepsilon X+(1-N) \gamma \varepsilon X
\end{aligned}
$$

In reality, the local government has nature information advantage which makes it difficult for the central government to monitor its behavior. It's possible that the central government can't find the rent-seeking activity although the central government take measures of supervision. Here we introduce a new parameter $\mu$ to describe the possibility of this kind of situation, and get a new game situation.

$\mathrm{V}$. There is rent-seeking behavior between the local government and the real estate developers, while the central government supervises the implementation 
of the local government but doesn't find its irregularities. In this situation, the local government can get the extra rent $\beta \varepsilon X$, and the real estate developer can also earn extra revenue of $\gamma_{\varepsilon} X$ before the rent. Besides, the central government need to pay A for the cost of supervision and pay $\omega \varepsilon X$ for the negative social utility. The payment is showed below:

$$
\begin{aligned}
& U C_{5}=(1-\varepsilon) \alpha k X-A-\omega \varepsilon X \\
& U L_{5}=(1-\varepsilon)(1-\alpha) k X+\beta \varepsilon X \\
& U D_{5}=Q_{0}-\beta \varepsilon X+\gamma \varepsilon X
\end{aligned}
$$

Figure 1 shows the decision tree of the three objects in the real estate market.

\subsection{The Solution and Analysis of the Game Equilibrium}

Based on the analysis above, taking the probability of the supervision of central government $(q)$, the probability of the rent-seeking activity between local government and the real estate developers $(p)$ and the probability of the situation that the central government find the irregularity of local government $(\mu)$ into consideration, we can get the expected revenue of the three participants in the tri-game.

A. In the case of a given $p$ value, the expected revenue of the central government is as follows:

$$
\begin{aligned}
U C= & (1-p)(1-q) U C_{1}+p(1-q) U C_{2}+(1-p) q U C_{3} \\
& +p q \mu U C_{4}+p q(1-\mu) U C_{5}
\end{aligned}
$$

In order to maximize the revenue of the central government, we take the first order partial derivative of $U C$ about $q$, and get the following result:

$$
\partial U C / \partial q=-(1-p) U C_{1}-p U C_{2}+(1-p) U C_{3}+p \mu U C_{4}+p(1-\mu) U C_{5}
$$

Put the payment in each game situation we described above in to formula (7), we can get the following result:

$$
\partial U C / \partial q=p \mu \varepsilon X(M \beta+N \gamma+\omega)-A
$$

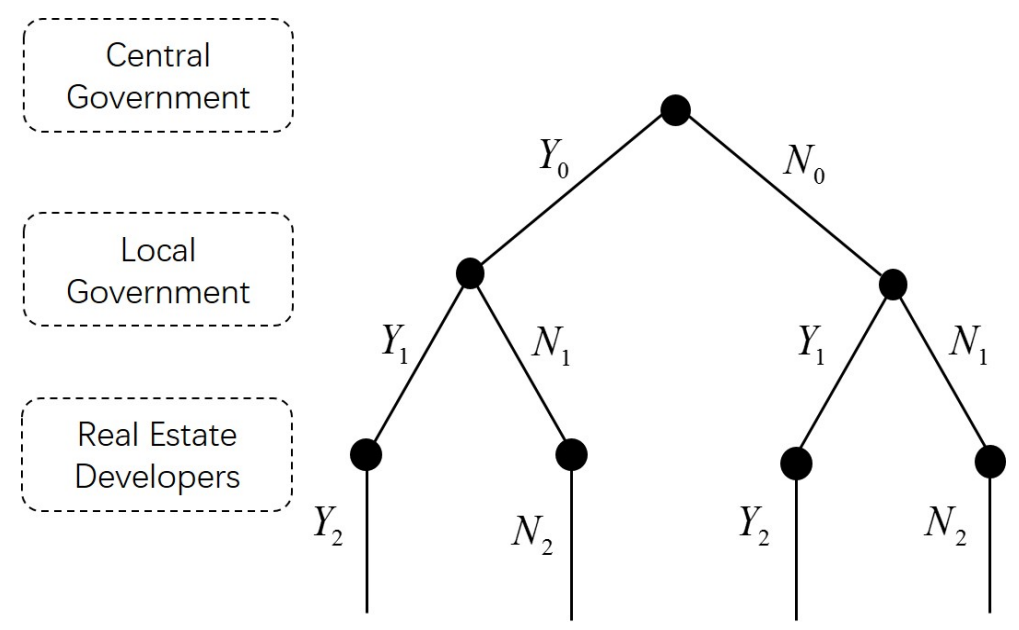

Figure 1. Decision tree of the three objects. 
When the first order partial derivative is equal to zero, which means that the central government get the equilibrium in the game, we get the best probability for the local government and the developers to have rent-seeking activities, and it can be written like this: $p^{*}=A /\{\mu \varepsilon X(M \beta+N \gamma+\omega)\}$.

From the result we can see that once $p>p^{*}$, the best choice for the central government is to supervise the local government; otherwise, it doesn't. When $p=p^{*}$, the revenue will be the same no matter the central government supervises or not. Further, the value of $p$ can be changed if the value of $A, \mu$, $M$ and $N$ changes, It will increase if $A$ rise, but it will decrease along with the drop of $\mu, M$ or $N$. As a result, it's better for the central government to reduce the cost of supervision and strengthen the penalties for the rent-seeking activity. Moreover, it should improve the quality of supervision to decrease of the probability of the irregularity of the local government, so that the macro-control policy can be implemented better.

B. In the case of a given $q$ value, the expected revenue of the local government is as follows:

$$
\begin{aligned}
U L= & (1-p)(1-q) U L_{1}+p(1-q) U L_{2}+(1-p) q U L_{3} \\
& +p q \mu U L_{4}+p q(1-\mu) U L_{5}
\end{aligned}
$$

In order to maximize the revenue of the local government, we take the first order partial derivative of $U L$ about $p$, and get the following result:

$$
\partial U L / \partial p=\varepsilon X[\beta-(1-\alpha) k]-q \mu M \beta \varepsilon X
$$

When the first order partial derivative is equal to zero, which means that the local government get the equilibrium in the game, we get the best probability for the central government to supervise the local government, and it can be written like this: $q^{*}=\frac{1}{\mu M}\left(1-\frac{1-\alpha}{\beta} k\right)$.

From the result, we can see that once $q>q^{*}$, the best choice for the local government is to strictly implement the policy without rent-seeking activities with the developers; otherwise, the local government will have the incentive to cooperate with the developer to seek for more benefits. When $q=q^{*}$, the revenue will be the same no matter the local government implement the policy or not. Further, the value of $q$ can be changed if the value of $\mu, M$ and $\alpha$ changes, It has negative relationship with the effectiveness of supervision and the punishment coefficient of local government, while has positive relationship with the revenue share for the central government once the policy is completely implemented. As a result, it's better for the central government to rise its revenue share properly and decrease the probability of supervision.

C. In the case of a given $q$ value, the expected revenue of the real estate developer is as follows:

$$
\begin{aligned}
U D= & (1-p)(1-q) U D_{1}+p(1-q) U D_{2}+(1-p) q U D_{3} \\
& +p q \mu U D_{4}+p q(1-\mu) U D_{5}
\end{aligned}
$$

In order to maximize the revenue of the real estate developers, we take the 
first order partial derivative of $U D$ about $p$, and get the following result:

$$
\partial U D / \partial p=\varepsilon X[\gamma-\beta-q \mu N \gamma]
$$

When the first order partial derivative is equal to zero, which means that the real estate developers get the equilibrium in the game, we get the best probability for the central government to supervise the local government, and it can be written like this: $q^{*}=\frac{\gamma-\beta}{N \mu \gamma}$.

From the result, we can see that once $q>q^{*}$, the best choice for the real estate developers is that they don't have rent-seeking activities with the local government; otherwise, the real estate developers will have the incentive to cooperate with the local government to seek for more benefits. When $q=q^{*}$, the revenue will be the same no matter they have rent-seeking activities or not. Further, the value of $q$ can be changed if the value of $\mu$ and $N$ changes, It has negative relationship with the effectiveness of supervision and the punishment coefficient of local government, while has positive relationship with the revenue share for the central government once the policy is completely implemented. It's better for the central government to strengthen the punishment for the real estate developers to decrease the rent-seeking activities.

Based on the analysis above, we can get the equilibrium of the mix strategy Nash game among the central government, local government and the real estate developers:

$$
\left\{\begin{array}{l}
p^{*}=A /\{\mu \varepsilon X(M \beta+N \gamma+\omega)\} \\
q^{*}=\frac{1}{\mu M}\left(1-\frac{1-\alpha}{\beta} k\right)
\end{array}\right.
$$

It means that in the case of giving priority to the effectiveness of local government, the probability for the central government to supervise is $q^{*}=\frac{1}{\mu M}\left(1-\frac{1-\alpha}{\beta} k\right)$, while the probability for the local government to have rent-seeking activities is $p^{*}=A /\{\mu \varepsilon X(M \beta+N \gamma+\omega)\}$

Otherwise,

$$
\left\{\begin{array}{l}
p^{*}=A /\{\mu \varepsilon X(M \beta+N \gamma+\omega)\} \\
q^{*}=\frac{\gamma-\beta}{N \mu \gamma}
\end{array}\right.
$$

It means that in the case of giving priority to the effectiveness of the real estate developers, the probability for the central government to supervise is $q^{*}=\frac{\gamma-\beta}{N \mu \gamma}$, while the probability for the local government to have rent-seeking activities is

$$
p^{*}=A /\{\mu \varepsilon X(M \beta+N \gamma+\omega)\}
$$

All in all, in order to decrease the probability for the local government and the real estate developers to have rent-seeking activities, it's better for the central government to decrease the supervision cost without damage its quality, and rise 
the punishment for their irregularity.

\section{Conclusions and Suggestions}

Through the analysis of the interests and behaviors of stakeholders, we found that once the housing price control policy implemented by the central government was strictly enforced, it would curb the soaring housing prices and suppress speculative demand effectively. However, there is a lack of incentives for local governments to crack real estate prices down. Because of the absence of regulation, local governments and the real estate developers have the motivation of rent-seeking. On the one hand, real estate developers could chase for more interests under higher housing price; on the other hand, the local government can get more benefit in the cooperation with the real estate developers. As a result, the separation of regional interests and central co-ordination not only reduce the impact of house price regulation policy, but also threaten overall welfare of the society ultimately.

The result of the tri-game shows that central government tends to release the supervision as their profits will be affected along with the improvement of regulatory costs, meanwhile, the local governments and property developers are more likely to have rent-seeking behaviors. Conversely, if central government tightens up the management, the irregularities of local governments and property developers will decline with the increase of the opportunity cost of rentseeking. Last but not least, the central government should strive to improve their own regulatory efficiency in order to suppress violations as seriously as possible.

According to the analysis of the above problems, we put forward the following suggestions: 1) Change the current regulatory system and strengthen the supervision function of third-party such as media. 2) Improve the appraisal system of government performance. The excessive pursuit of rapid growth of GDP is a major reason why the local government to promote high property prices. 3) Reform the existing system of profit distribution.

Admittedly, there are some deficiencies in this article. Due to the fact that there are so many participants in real estate market, meanwhile, the complex situation of this market is not only caused by one or two objects but the multi-game among various stakeholders, we only discussed three main objects in the real estate market without the consideration of the consumers, the bank and many other participants so as to simplify the model.

\section{Acknowledgements}

We are very grateful to the anonymous reviewers that have given us a lot of helpful suggestions to make the paper better. Thank you very much.

\section{References}

[1] Du, L. and Yao, Y.C. (2002) The Economics Paradox and the Analysis of China's Real Estate Market. Journal of Capital University of Economics and Business, 1, 1416. 
[2] Liu, F. (2006) The Real Estate Market Disequilibrium Model in China-Based on an Empirical Analysis of the Data from 1987 to 2004. Journal of Postgraduates in Zhongnan University of Economics and Law, 1, 52-57.

[3] Jin, L. (2007) Look at the Development of Housing Market by Supply and Demand Equilibrium Theory: The Case Study of Songjiang in Shanghai. The Harmonious City Planning-Proceedings of 2007 Annual Meeting of China's Urban Planning, 1373-1379.

[4] Ding, Y., Li, C.M. and Ding, L.Y. (2008) Analysis of Macroeconomic Regulatory Policy of the Real Estate Market under Equilibrium Theory. Statistics and Decision, 8, 48-51.

[5] Que, B. (2010) The Disequilibrium Analysis with Supply and Demand of Real Estate Market. Southwestern University of Finance and Economics, Chengdu.

[6] Guo, H.T. (2013) The Formation Mechanism of the Real Estate Price: Based on the Perspective of the Balance of Supply and Demand. Academic Exchange, 3, 138-141.

[7] Chen, J.X. (2011) The Analysis of the Games between the Central and Local Governments in Real Estate Market Macroeconomic Regulation and Control. Zhejiang Land \& Resources, 2, 48-51.

[8] Peng, F.P. and Fang, Q.Y. (2003) The Analysis of the Game between Real Estate Developers and Local Government. Value Engineering, 5, 10-12.

[9] Wang, Z.L., et al. (2008) Dynamic Game with Asymmetric Information in Real Estate Market. Systems Engineering, 12, 8-13.

[10] Yu, J.Y. (2009) Analysis of the Game between Central and Local Government in the Regulation and Control of House Price. China Economist, 2, 263-264.

[11] Ding, J. (2011) Analysis of the Game of Real Estate Market Interest Subjects. China Opening Journal, 6, 35-38.

[12] Yang, J.R. and Sun, B.Y. (2004) Policy Factors and China's Real Estate Market Development Path-Analysis of the Tripartite Game Including Government, Developers and Consumers. The Study of Finance and Economics, 4, 130-139.

[13] Liang, Q.G. (2011) The Game of Real Estate Macroeconomic Regulation and Control. Economic Vision, 7, 132-133.

[14] Huai, J.J., Liu, X.M. and Lei, H.M. (2007) The Analysis of the Game between League for Four and Confrontation in Regulation of the Real Estate Market in China. Systems Engineering, 12, 34-41.

[15] Gao, P. (2011) Central Government and Local Government Adjust to Control a Medium Game Problem a Research in the Real Estate Market. Master Thesis, Southwest Jiaotong University, Chengdu.

[16] Wang, Z. (2013) Analysis on Real Estate Market by Game Theory. Shanxi University, Taiyuan.

[17] Peng, K.T. (2008) The Performance of Promoting Urban Housing Market Macroeconomic Regulation and Control-Based on the Analysis of Space Perspective. City Planning Review, 9, 21-27. 
Submit or recommend next manuscript to SCIRP and we will provide best service for you:

Accepting pre-submission inquiries through Email, Facebook, LinkedIn, Twitter, etc. A wide selection of journals (inclusive of 9 subjects, more than 200 journals)

Providing 24-hour high-quality service

User-friendly online submission system

Fair and swift peer-review system

Efficient typesetting and proofreading procedure

Display of the result of downloads and visits, as well as the number of cited articles Maximum dissemination of your research work

Submit your manuscript at: http://papersubmission.scirp.org/

Or contact ojapps@scirp.org 